\title{
Study of antinociceptive effect of ketamine in acute and neuropathic pain models in rats
}

\author{
Nina Dimitrova Doncheva ${ }^{1, A-D, F}$, Liliya Vasilevaa, ${ }^{1,2,-E}$, Kremena Saracheva ${ }^{1, B-D}$, Darinka Dimitrova ${ }^{3,2, A-C}$, Damyanka Getova ${ }^{2, E, F}$ \\ 1 Department of Pharmacology and Drug Toxicology, Faculty of Pharmacy, Medical University of Plovdiv, Bulgaria \\ ${ }^{2}$ Laboratory of Neuropharmacology, Technological Center for Emergency Medicine (TCEMED), Plovdiv, Bulgaria \\ ${ }^{3}$ Department of Pharmacology and Clinical Pharmacology, Faculty of Medicine, Medical University of Plovdiv, Bulgaria \\ A - research concept and design; B - collection and/or assembly of data; $\mathrm{C}$ - data analysis and interpretation; \\ $D$ - writing the article; $E$ - critical revision of the article; $F$ - final approval of the article
}

Address for correspondence

Nina Dimitrova Doncheva

E-mail: ninanina1972@abv.bg

Funding sources

None declared

Conflict of interest

None declared

Received on December 21, 2017

Reviewed on March 26, 2018

Accepted on August 9, 2018

Published online on December 18, 2018

Cite as

Doncheva N, Vasileva L, Saracheva K, Dimitrova D,

Getova D. Study of antinociceptive effect of ketamine

in acute and neuropathic pain models in rats. Adv Clin

Exp Med. 2019;28(5):573-579. doi:10.17219/acem/94143

D0I

10.17219/acem/94143

Copyright

Copyright by Author(s)

This is an article distributed under the terms of the

Creative Commons Attribution Non-Commercial License

(http://creativecommons.org/licenses/by-nc-nd/4.0/)

\begin{abstract}
Background. Glutamate N-methyl-D-aspartate (NMDA) receptors are known for their importance in the perseverance of chronic neuropathic pain. Ketamine, an intravenous anesthetic agent, is a non-competitive blocker of NMDA receptors. Applied in anesthetic doses, ketamine has anti-nociceptive effects in various animal pain models.
\end{abstract}

Objectives. The objective of this study was to investigate the anti-nociceptive effect of ketamine in acute and neuropathic pain models in rats.

Material and methods. To study the anti-nociceptive effect of ketamine on acute pain, 40 Wistar rats were divided into 5 groups $(n=8)$ : control, positive control group and 3 experimental groups treated intraperitoneally (ip.) with $30 \mathrm{mg} / \mathrm{kg} \mathrm{bw}, 40 \mathrm{mg} / \mathrm{kg}$ bw and $50 \mathrm{mg} / \mathrm{kg}$ bw ketamine, respectively. The anti-nociceptive effect was evaluated in hot plate, analgesy-meter and formalin tests. The model of neuropathic pain was induced by left sciatic nerve ligation. Twenty-four Wistar rats were divided into 3 groups $(n=8)$ : sham-control group, model group and ketamine-treated group subsequently tested in hot plate and analgesy-meter tests.

Results. In the hot plate test, the rats treated with ketamine presented increased reaction latency at the $120^{\text {th }}$ min and $180^{\text {th }}$ min compared to the controls. In the analgesy-meter test, ketamine produced an antinociceptive effect at the $60^{\text {th }}$ min compared to the controls. In the formalin test, the paw licking time across the early phase of testing was reduced in the rats treated with the 2 higher doses of ketamine. In a neuropathic pain model, ketamine increased the reaction latency at the $120^{\text {th }}$ min and $180^{\text {th }}$ min compared with the model group in the hot plate test. In the analgesy-meter test, in the ketamine-treated animals the paw withdrawal threshold increased at the $60^{\text {th }}$ min compared with the model group.

Conclusions. Our results suggest that ketamine produces peripheral anti-nociceptive effect in an acute pain model. Also, it relieves thermal and mechanical allodynia after 14 days of treatment in a neuropathic pain model.

Key words: ketamine, rats, acute pain, neuropathic pain 
Pain is a subjectively unpleasant sensory and emotional experience caused by actual or potential tissue damage. It is classified by different criteria: duration, pathophysiology and anatomical localization. Depending on its duration, pain can be classified as acute or chronic. According to the pathophysiological mechanisms that cause it, pain could be nociceptive or neuropathic. ${ }^{1}$

Pain management is of great importance in clinical practice. Conditions involving acute or chronic pain account for a large proportion of presentations to the family general practitioner and in the emergency ward. There is evidence of the critical role of the excitatory neurotransmitter glutamate in the development and perseverance of chronic neuropathic pain. ${ }^{2}$ Glutamate acts pre- and postsynaptically through the activation of diverse receptors: N-methylD-aspartate (NMDA), alpha-amino-3-hydroxy-5-methyl-4-isoxazolepropionic acid (AMPA), kainate (KA), and metabotropic receptors.

Ketamine, an intravenous anesthetic agent, is a noncompetitive blocker of NMDA receptors. ${ }^{3}$ Ketamine produces anti-inflammatory, antioxidant and immunosuppressive effects. The mechanism of action of ketamine has been associated with binding to the phencyclidine site in the glutamate receptor. ${ }^{4}$ It affects opioid, dopaminergic and cholinergic transmission. ${ }^{5}$ The effect on the glutamate mediation determines its analgesic, dissociative and neuroprotective effects, and by acting on opioid receptors, ketamine produces dysphoric effects. The sympathomimetic action is mediated by the response of the central and peripheral monoaminergic systems. Blocking the central and peripheral cholinergic mediation contributes to the anesthetic and psychomimetic action. ${ }^{6}$ Ketamine has been shown to antagonize the effects of dopamine on dopamine type 2 (D2) receptors. ${ }^{7}$ Ketamine supplied in anesthetic doses has neuroprotective effects in various animal models of brain injury. This effect is caused by a blockage of NMDA receptors and reduced influx of $\mathrm{Ca}^{2+}$ ions through the receptor channels. ${ }^{8}$

Chronic pain is caused by tissue damage that continues after the lesion has healed. For this reason, it is not caused by the activation of nociceptors, has no protective effect and lowers the quality of life of patients.

Neuropathic pain has been described as "the most terrible of all tortures which a nerve wound may inflict". The damaged nerve fibers in neuropathic pain send incorrect signals to the pain centers. Neuropathic pain is characterized by sensory abnormalities such as an unpleasant abnormal sensation (dysesthesia), an increased response to painful stimuli (hyperalgesia) and pain in response to a stimulus that does not normally provoke pain (allodynia).

The present study aims to investigate the anti-nociceptive effect of ketamine in acute and neuropathic pain models in rats.

\section{Material and methods}

\section{Animals}

Male Wistar rats with an average weight between $200 \mathrm{~g}$ and $220 \mathrm{~g}$ were used. The animals were housed under standard laboratory conditions: a 12:12 h light/dark cycle, room temperature of $26 \pm 1^{\circ} \mathrm{C}$, and free access to food and water. After surgery, the animals were housed separately. The experiments were performed after the protocol was approved by the Animal Ethics Committee of the Medical University of Plovdiv (Bulgaria) and Bulgarian Food Safety Agency, and in compliance with the European Directive 2010/63/EU.

\section{Experimental design}

The anti-nociceptive effect of repeated doses of ketamine was studied in the $1^{\text {st }}$ series of experiments. The animals were randomized into 5 groups $(n=8)$. The control group received only saline, the positive control group was treated with metamizole $150 \mathrm{mg} / \mathrm{kg}$ bw, and the 3 experimental groups were treated with ketamine in doses of $30 \mathrm{mg} / \mathrm{kg} \mathrm{bw}$, $40 \mathrm{mg} / \mathrm{kg}$ bw and $50 \mathrm{mg} / \mathrm{kg}$ bw, respectively. All agents were dissolved in saline as a vehicle and injected intraperitoneally (ip.) for 14 days. Three nociceptive tests were used: hot plate test, analgesy-meter and formalin test.

The effect of repeated doses of ketamine on the neuropathic pain model was studied in the $2^{\text {nd }}$ series of experiments. A chronic constriction injury of the sciatic nerve model was used. After the operation, the animals were randomly allocated to receive ip. saline (model group) or ketamine $50 \mathrm{mg} / \mathrm{kg}$ bw. To study the analgesic effect of ketamine in neuropathic pain, hot plate and analgesy-meter tests were used.

\section{Hot plate test}

The original hot plate set up (Ugo Basile S.R.L., Germonio, Italy) was used. The temperature of the hot plate surface was set to $55 \pm 0.5^{\circ} \mathrm{C}$. The reaction latency as well as the time between when the animals were placed and the onset of paw-licking or jumping behaviors were measured in seconds. To minimize tissue damage, a cut-off time of $30 \mathrm{~s}$ was adopted.

\section{Analgesy-meter test}

Mechanical nociceptive testing was conducted using an analgesy-meter (Ugo Basile). The rats were tested at the $60^{\text {th }} \mathrm{min}, 120^{\text {th }} \mathrm{min}$ and $180^{\text {th }} \mathrm{min}$ after ip. administration of the test substance. The force of the pressure was calibrated at $10 \mathrm{~g} / \mathrm{cm}$ at a max force of $250 \mathrm{~g}$. The force of the pressure at which the animal withdrew the test paw was expressed in conditional units $(\mathrm{cm})$. The maximum possible pressure was $25 \mathrm{~cm}$. 


\section{Formalin test}

In this method, formalin $(0.1 \mathrm{~mL}, 2 \%)$ was injected into the plantar surface of the left hind paw. Each animal was placed in an observation chamber and the nociceptive response was recorded for a period of $30 \mathrm{~min}$. The sum of time (in seconds) spent licking and biting the injected paw in the first $10 \mathrm{~min}$ is known as the early or acute phase. The period between $20-30 \mathrm{~min}$ is considered the late or chronic phase.

\section{Chronic pain model}

The model of neuropathic pain was designed according to the model of chronic constriction injury (CCI) of the sciatic nerve described by Bennett and Xie. ${ }^{9}$ The animals were anesthetized with pentobarbital sodium (50 mg/kg bw, ip.), which provided anesthesia for 20-40 min. The left sciatic nerve was found deep within the biceps femoral muscle. The nerve was gently removed from the surrounding tissues and 2 ligatures $2 \mathrm{~mm}$ apart were made. The sham control was subjected to identical left foot dissection without ligation of the sciatic nerve. After the operation, the animals were allowed to recover for 1 week.

\section{Statistical analysis}

The data obtained from the nociceptive tests was statistically processed with SPSS v. 17.0 (IBM Corp., Armonk, USA). Results were represented as the mean \pm standard error of the mean (SEM). Comparison of the results for each score to the respective control group was performed using an independent sample t-test. A value of $\mathrm{p}<0.05$ was considered statistically significant. The Shapiro-Wilk test was applied as a normality test. In distributions different from normal, the Mann-Whitney U test was used for inter-group evaluation.

\section{Results}

\section{Acute pain model}

\section{Effects on thermal nociception}

The average latency of the controls in the hot plate test was between $7 \mathrm{~s}$ and $10 \mathrm{~s}$. The metamizole-treated rats significantly $(\mathrm{p}<0.05)$ increased the reaction latency at the $120^{\text {th }} \mathrm{min}$ and the $180^{\text {th }}$ min compared with the control group. The animals treated with ketamine in all doses showed an increase in latency at the $120^{\text {th }} \mathrm{min}$ and $180^{\text {th }}$ min $(\mathrm{p}<0.05)$ compared with the respective day controls (Fig. 1).

\section{Effects on mechanical nociception}

In the analgesy-meter test, the control animals' average pressure reaction was between $7 \mathrm{~cm}$ and $9 \mathrm{~cm}$. The animals treated with metamizole showed a significant increase $(\mathrm{p}<0.05)$ in latency at the $60^{\text {th }} \mathrm{min}, 120^{\text {th }} \mathrm{min}$ and $180^{\text {th }}$ min compared with the controls. The lower doses of ketamine of $30 \mathrm{mg} / \mathrm{kg}$ bw and $40 \mathrm{mg} / \mathrm{kg}$ bw did not exert significant changes on the reaction latency. The rats treated with ketamine in a dose of $50 \mathrm{mg} / \mathrm{kg}$ bw increased the paw withdrawal threshold at the $60^{\text {th }}$ min $(\mathrm{p}<0.05)$ compared with the control group (Fig. 2).

\section{Effects on chemical nociception}

In the controls, the duration of paw licking across the early phase was $35.37 \pm 4.02 \mathrm{~s}$, and $47.75 \pm 6.3 \mathrm{~s}$ across the late phase. The paw licking time did not decrease in the metamizole-treated group during the 2 phases of the test compared to the control group. In the group treated with ketamine in a dose of $30 \mathrm{mg} / \mathrm{kg}$ bw, the time of paw licking did not significantly change in either phase of the formalin test compared with the controls. The paw licking time in the animals treated with the 2 higher doses of ketamine (40 mg/kg bw and $50 \mathrm{mg} / \mathrm{kg} \mathrm{bw}$ ) decreased only across the

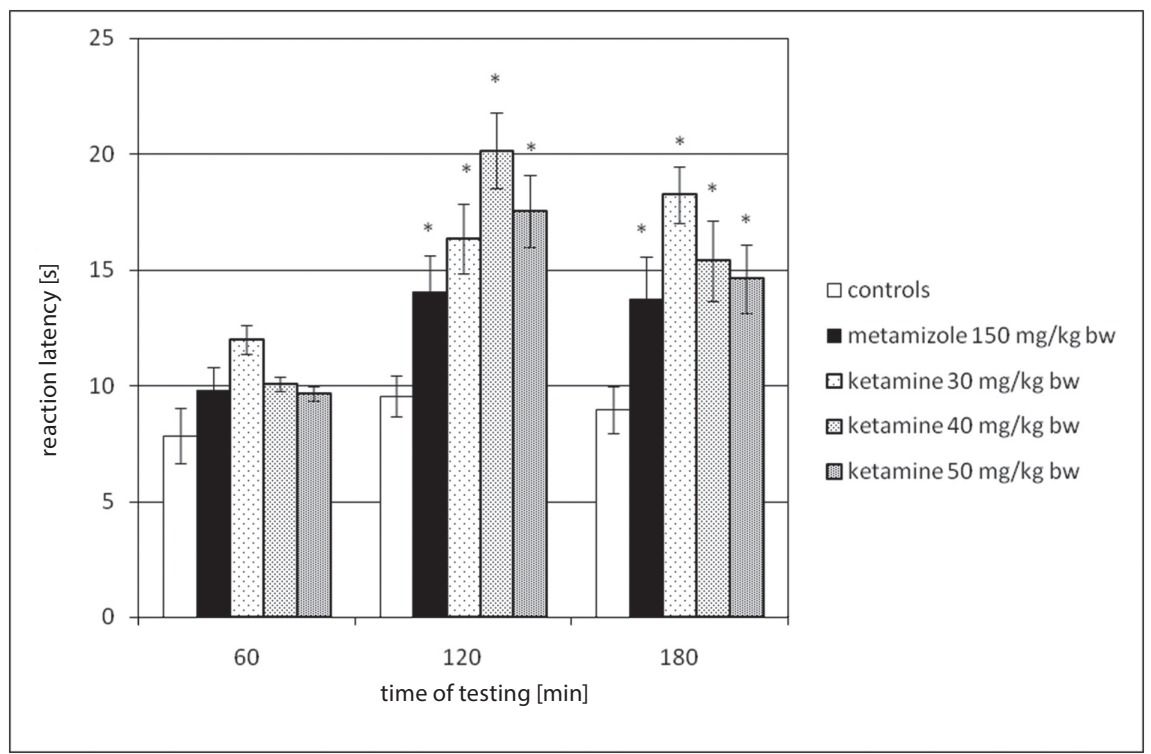

Fig. 1. Anti-nociceptive effect of ketamine in hotplate test and acute pain model

${ }^{*} p<0.05$ compared with the control group. 

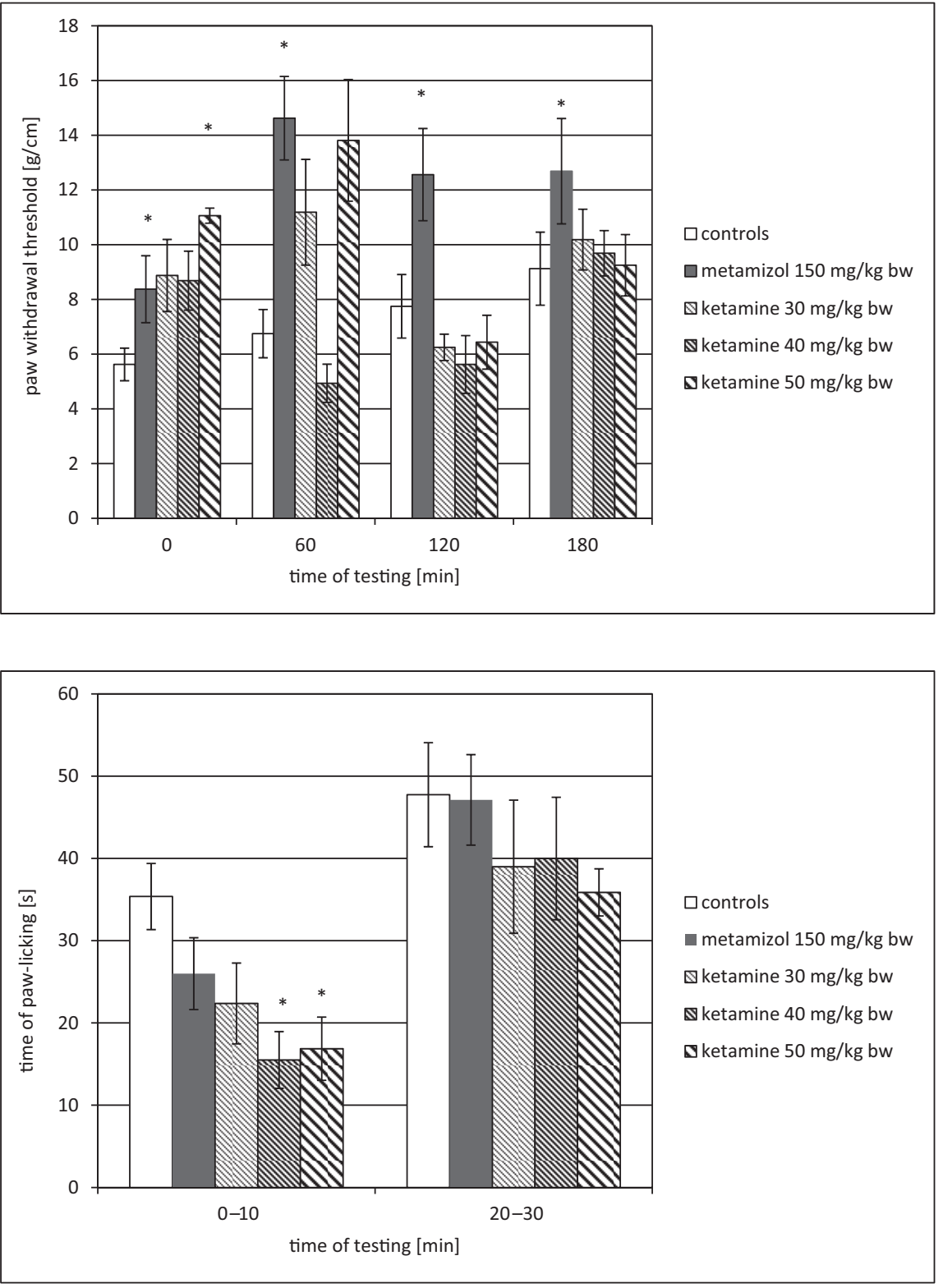

Fig. 2. Anti-nociceptive effect of ketamine in analgesy-meter test and acute pain model ${ }^{*} p<0.05$ compared with the control group.

Fig. 3. Anti-nociceptive effect of ketamine in formalin test

* $p<0.01$ compared with the control group. early phase of testing $(\mathrm{p}<0.01)$ compared with the control group (Fig. 3).

\section{Neuropathic pain model}

\section{Effects on thermal nociception}

In the hot plate test, the average latency of the sham control was between $14 \mathrm{~s}$ and $18 \mathrm{~s}$. The model group significantly increased the latency time at the $60^{\text {th }} \min (\mathrm{p}<0.01)$ compared to the sham control. The animals treated with ketamine at a dose of $50 \mathrm{mg} / \mathrm{kg}$ bw significantly increased latency at the $120^{\text {th }} \mathrm{min}$ and $180^{\text {th }} \min (\mathrm{p}<0.05)$ compared to the model group (Fig. 4).

\section{Effects on mechanical nociception}

In the mechanical paw pressure test, the average latency of the sham control was between $9 \mathrm{~cm}$ and $12 \mathrm{~cm}$.
The model group did not show a significant increase in the pressure reaction as compared to the sham control. The group treated with ketamine $50 \mathrm{mg} / \mathrm{kg}$ bw showed increased ( $\mathrm{p}<0.05$ ) latency of pressure reaction at the $60^{\text {th }}$ min as compared to the model group (Fig. 5).

\section{Discussion}

The present study showed that ip. administration of ketamine produced an anti-nociceptive effect in models of acute and neuropathic pain. Ketamine exhibited more potent activity in regard to inhibiting thermal nociception (allodynia) than mechanical nociception. Thus, we assume that systemic ketamine does have an analgesic effect in normal and neuropathic pain conditions. 

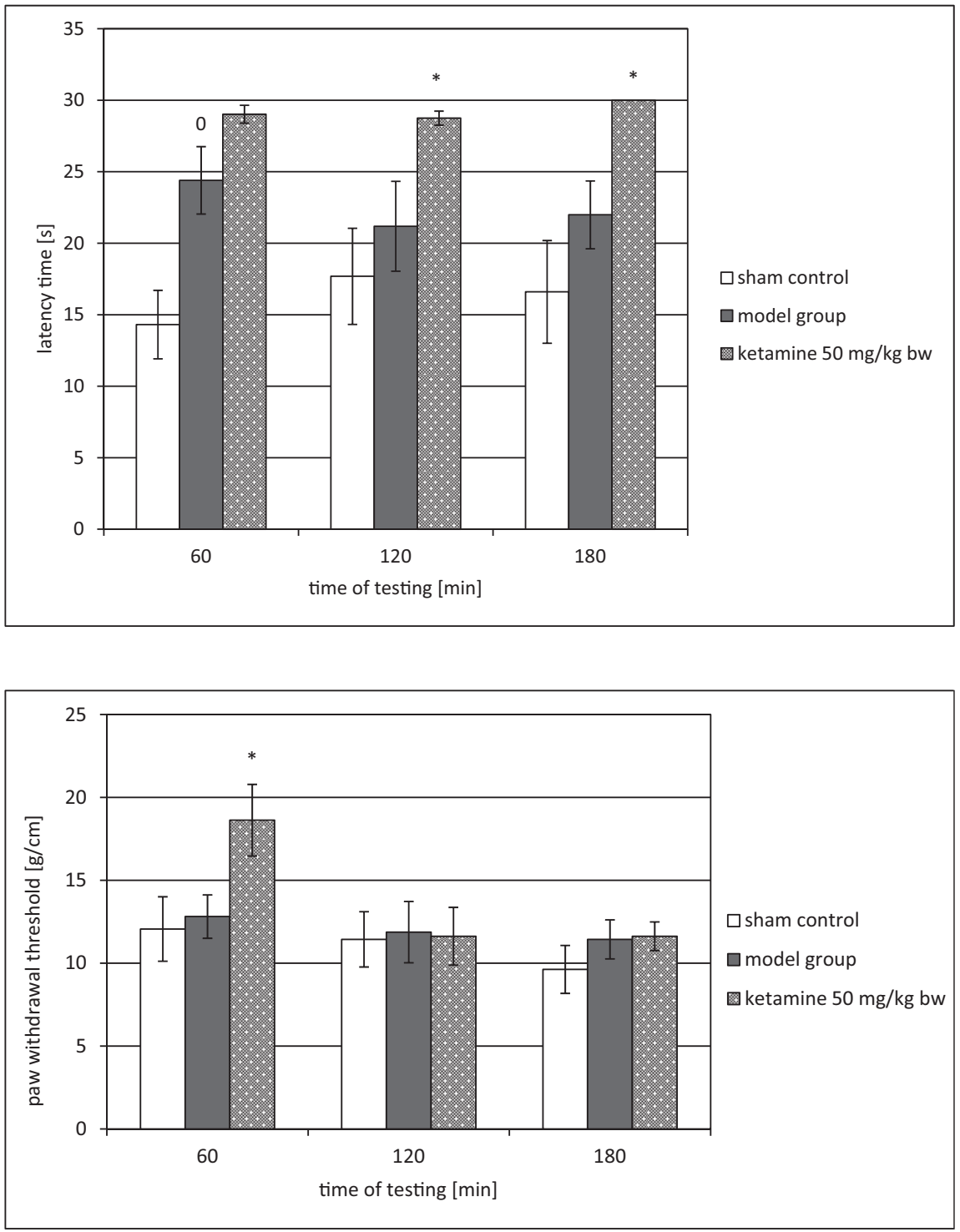

Fig. 4. Anti-nociceptive effect of ketamine in hotplate test and neuropathic pain model

${ }^{0} p<0.01$ compared with sham control; * $p<0.05$ compared with the model group.

\section{Anti-nociceptive effect of ketamine on acute pain}

In the present study, all doses of ketamine showed a significant anti-nociceptive effect in the hot plate test. Koizuka et al. found that in normal rats ketamine produces anti-nociceptive effects through the activation of monoaminergic descending inhibitory pathways for acute thermal pain. ${ }^{10}$ Our findings are in agreement with those of other authors, who reported a well-defined anti-nociceptive effect of ketamine in other nociceptive test with thermal stimulus - infrared rays. ${ }^{11}$ We also observed that the highest dose of systemic ketamine produced early anti-nociception in the acute pain model with mechanical stimulus. The results of the present study are consistent with previously reported results. ${ }^{12}$ This effect has been reported at doses lower than ours $-7.5 \mathrm{mg} / \mathrm{kg}$ bw and $10 \mathrm{mg} / \mathrm{kg}$ bw single dose, as well as in a model of hyperalgesia caused by intraplantarly injected prostaglandin E2.
The analgesic effect of ketamine was found in postoperative pain in a number of clinical and experimental studies. ${ }^{13}$

The nociception response in the formalin test is biphasic. In the initial acute period of about $10 \mathrm{~min}$ (phase 1), the registered behavioral changes were due to axially activated primary afferent nerve terminals. These changes are mediated by activation of the transient receptor potential ankyrin 1 (TRPA1) channels. ${ }^{14}$ The $2^{\text {nd }}$ phase of the formalin test reflects the central sensitization of neurons in the dorsal horn and peripheral sensitization of nociceptors by formalin-induced local inflammatory response. ${ }^{15}$ Our results indicate that ip. treatment with higher doses of ketamine significantly reduced nociceptive scores in the early phase of the formalin test. In contrast, Bulutcu et al. found a significant anti-nociceptive effect in the single systemic intrathecal administration of ketamine only during the late phase of the formalin test. ${ }^{12}$ Perhaps this difference is due to the different route of administration of ketamine. Our results allow the conclusion that ketamine can be a reliable 
analgesic in pain caused by chemical agents immediately after the onset of the damage rather than at a later stage in the development of the pain response.

\section{Anti-nociceptive effect of ketamine on neuropathic pain}

The CCI of the sciatic nerve is associated with intraneural edema, focal ischemia and Wallerian degeneration. Behavioral changes, like mechanical and thermal hyperalgesia, chemical hyper-reactivity and cold allodynia, are likely to develop within a week. ${ }^{17}$

Traumatic injury of the sciatic nerve in rats is a commonly used model for the study of peripheral nerve damage. There is data in the literature regarding the involvement of NMDA receptors in the pathogenesis of pain in peripheral tissues or nerves. ${ }^{18,19}$ These receptors are found in the peripheral myelinated and unmyelinated somatic nerve fibers, spinal cord and cerebellum. ${ }^{20}$ They play a role in the process of central sensitization. Accordingly, NMDA receptor antagonists such as ketamine effectively reduce pain responses in animal models and influence pain in clinical trials. ${ }^{19,21}$

In the model of neuropathic pain, ketamine at the studied dose showed an anti-nociceptive effect in the "hot plate" test. Burton et al. found that ketamine administration resulted in a sustained delay in the development of allodynia associated with spinal nerve damage in rats. ${ }^{22}$ Other authors have found that the introduction of the short-acting NMDA antagonist reduces the development of opiate tolerance, a condition associated with the development of NMDA receptor hyperalgesia. ${ }^{23}$ In experimental models, intrathecal or systemic administration of ketamine reduces hyperalgesia and inflammatory disease caused by peripheral nerve damage. ${ }^{24,25}$ Other authors have reported that ketamine does not exhibit an anti-nociceptive effect in acute thermal pain in rats when administered intrathecally. ${ }^{26}$ The anti-nociceptive effect of ketamine was also found in acute pain observed in thermal pain stimulus applied to the tail. ${ }^{27}$ This effect results from a blockage of NMDA receptors and reduced influx of $\mathrm{Ca}^{2+}$ ions through the receptor channel.

In the nociceptive test with mechanical paw pressure, ketamine showed an early and short-lasting analgesic effect. Koizuka et al. found that ketamine reduced the hypersensitivity of neurons at an early stage in postoperative pain model in rats. ${ }^{10}$ The same authors found that pretreatment with the $\alpha 2$-receptor or serotonin receptor antagonists reduced the effect of ketamine in this model. These results suggest that activation of monoaminergic downstream inhibitory pathways occupies an important place in the mechanisms of analgesic efficacy of ketamine in this pain model.

Mei et al. reported that in a model of neuropathic pain induced by spinal cord ligation, the intrathecal introduction of ketamine reduced mechanical allodynia. ${ }^{28}$ These authors observed that the intrathecal injection reduced astrocytic activity in the dorsal neurons in the lumbar spinal cord, as measured by the immunohistochemical method. These results allowed them to conclude that the inhibition of astrocyte activation by blocking NMDA receptors on the astrocyte membrane is probably a new mechanism in the analgesic efficiency of ketamine at the spinal level.

Our results suggest that ketamine showed an anti-nociceptive effect in both the acute pain tests and chronic neuropathic pain model. Various experimental models of peripheral nerve damage have detected the involvement of nociceptive $\mathrm{C}$-fibers in mechanical and thermal hyperalgesia in neuropathic pain. Vogelaar et al. observed reduced mechanical and thermal sensitivity in the damaged area after damage to the sciatic nerve. ${ }^{17}$

\section{Conclusions}

In conclusion, the present study revealed that systemic administration of ketamine produced anti-nociception in models of acute pain. Ketamine relieved mechanical and thermal allodynia in a chronic neuropathic pain model. These observations make ketamine an attractive alternative in the treatment of acute and chronic pain.

\section{References}

1. Treede R-D. Chapter 1 Pain and hyperalgesia: Definitions and theories. Handb Clin Neurol. 2006;81:3-10. doi:10.1016/S0072-9752(06)80005-9

2. Chizh BA. Low dose ketamine: A therapeutic and research tool to explore N-methyl-D-aspartate (NMDA) receptor-mediated plasticity in pain pathways. J Psychopharmacol. 2007;21(3):259-271. doi:10. $1177 / 0269881105062484$

3. Kosson D, Klinowiecka A, Kosson P, et al. Intrathecal antinociceptive interaction between the NMDA antagonist ketamine and the opioids, morphine and biphalin. Eur J Pain. 2008;12(5):611-616. doi:10.1016/j. ejpain.2007.10.005

4. Harrison NL, Simmonds MA. Quantitative studies on some antagonists of N-methyl D-aspartate in slices of rat cerebral cortex. Br JPharmacol. 1985;84(2):381-391. http://www.ncbi.nlm.nih.gov/pubmed/ 2858237. Accessed July 3, 2017.

5. White J, Ryan C. Pharmacological properties of ketamine. Drug Alcohol Rev. 1996;15(2):145-155. doi:10.1080/09595239600185801

6. Adams HA. Mechanisms of action of ketamine [in German]. Anaesthesiol Reanim. 1998;23(3):60-63. http://www.ncbi.nlm.nih.gov/ pubmed/9707750. Accessed July 3, 2017.

7. Kapur S, Seeman P. Ketamine has equal affinity for NMDA receptors and the high-affinity state of the dopamine D2 receptor. Biol Psychiatry. 2001;49(11):954-957. http://www.ncbi.nlm.nih.gov/pubmed/ 11398792. Accessed July 3, 2017.

8. Himmelseher S, Durieux ME. Revising a dogma: Ketamine for patients with neurological injury? Anesth Analg. 2005;101(2):524-534. doi:10. 1213/01.ANE.0000160585.43587.5B

9. Bennett GJ, Xie YK. A peripheral mononeuropathy in rat that produces disorders of pain sensation like those seen in man. Pain. 1988;33(1): 87-107. http://www.ncbi.nlm.nih.gov/pubmed/2837713. Accessed July 3, 2017.

10. Koizuka S, Obata H, Sasaki M, Saito S, Goto F. Systemic ketamine inhibits hypersensitivity after surgery via descending inhibitory pathways in rats. Can J Anesth. 2005;52(5):498-505. doi:10.1007/BF03016530

11. Swartjes M, Morariu A, Niesters M, Aarts L, Dahan A. Nonselective and NR2B-selective N-methyl-d-aspartic acid receptor antagonists produce antinociception and long-term relief of allodynia in acute and neuropathic pain. Anesthesiology. 2011;115(1):165-174. doi:10.1097/ ALN.0b013e31821bdb9b 
12. Romero TR, Duarte ID. Involvement of ATP-sensitive K+ channels in the peripheral antinociceptive effect induced by ketamine. Vet Anaesth Analg. 2013;40(4):419-424. doi:10.1111/vaa.12024

13. Wang N, Fu Y, Ma H, Wang J. Clinical research regarding preemptive analgesic effect of preoperative ketamine after transurethral resection of prostate. Middle East J Anaesthesiol. 2015;23(3):295-300. http:// www.ncbi.nlm.nih.gov/pubmed/26860019. Accessed July 3, 2017.

14. McNamara CR, Mandel-Brehm J, Bautista DM, et al. TRPA1 mediates formalin-induced pain. Proc Natl Acad Sci. 2007;104(33):13525-13530. doi:10.1073/pnas.0705924104

15. Herrero JF, Laird JM, López-García JA. Wind-up of spinal cord neu rones and pain sensation: Much ado about something? Prog Neurobiol. 2000;61(2):169-203. http://www.ncbi.nlm.nih.gov/pubmed/ 10704997. Accessed July 3, 2017

16. Bulutcu F, Dogrul A, Güç MO. The involvement of nitric oxide in the analgesic effects of ketamine. Life Sci. 2002;71(7):841-853. http:// www.ncbi.nlm.nih.gov/pubmed/12074943. Accessed July 3, 2017.

17. Vogelaar CF, Vrinten DH, Hoekman MFM, Brakkee JH, Burbach JPH, Hamers FPT. Sciatic nerve regeneration in mice and rats: Recovery of sensory innervation is followed by a slowly retreating neuropathic pain-like syndrome. Brain Res. 2004;1027(1-2):67-72. doi:10.1016/j. brainres.2004.08.036

18. Chizh BA, Headley PM. NMDA antagonists and neuropathic pain - multiple drug targets and multiple uses. Curr Pharm Des. 2005; 11(23):2977-2994. http://www.ncbi.nlm.nih.gov/pubmed/16178757. Accessed July 3, 2017.

19. Fisher K, Coderre TJ, Hagen NA. Targeting the N-methyl-D-aspartate receptor for chronic pain management. Preclinical animal studies, recent clinical experience and future research directions. J Pain Symptom Manage. 2000;20(5):358-373. http://www.ncbi.nlm.nih. gov/pubmed/11068158. Accessed July 3, 2017.

20. Coggeshall RE, Carlton SM. Ultrastructural analysis of NMDA, AMPA and kainate receptors on unmyelinated and myelinated axons in the periphery. J Comp Neurol. 1998;391(1):78-86. doi:10.1002/(SICI)10969861(19980202)391:1<78::AID-CNE7>3.0.CO;2-O.
21. Du J, Zhou S, Coggeshall RE, Carlton SM. N-methyl-D-aspartateinduced excitation and sensitization of normal and inflamed nociceptors. Neuroscience. 2003;118(2):547-562. http://www.ncbi.nlm. nih.gov/pubmed/12699789. Accessed July 3, 2017.

22. Burton AW, Lee DH, Saab C, Chung JM. Preemptive intrathecal ketamine injection produces a long-lasting decrease in neuropathic pain behaviors in a rat model. Reg Anesth Pain Med. 24(3):208-213. http:// www.ncbi.nlm.nih.gov/pubmed/10338169. Accessed July 3, 2017.

23. Danysz W, Kozela E, Parsons CG, Sladek M, Bauer T, Popik P. Peripherally acting NMDA receptor/glycine B site receptor antagonists inhibit morphine tolerance. doi:10.1016/j.neuropharm.2004.11.005

24. Qian J, Brown SD, Carlton SM. Systemic ketamine attenuates nociceptive behaviors in a rat model of peripheral neuropathy. Brain Res. 1996;715(1-2):51-62. doi:10.1016/0006-8993(95)01452-7.

25. Klimscha W, Horváth G, Szikszay M, Dobos I, Benedek G. Antinociceptive effect of the $\mathrm{S}(+)$-enantiomer of ketamine on carrageenan hyperalgesia after intrathecal administration in rats. Anesth Analg. 1998; 86(3):561-565. http://www.ncbi.nlm.nih.gov/pubmed/9495415. Accessed July 3, 2017.

26. Kawamata T, Omote K, Sonoda H, Kawamata M, Namiki A. Analgesic mechanisms of ketamine in the presence and absence of peripheral inflammation. Anesthesiology. 2000;93(2):520-528. http://www.ncbi. nlm.nih.gov/pubmed/10910503. Accessed July 3, 2017.

27. Näsström J, Karlsson U, Post C. Antinociceptive actions of different classes of excitatory amino acid receptor antagonists in mice. Eur J Pharmacol. 1992;212(1):21-29. http://www.ncbi.nlm.nih.gov/ pubmed/1313371. Accessed July 3, 2017.

28. Mei X, Wang W, Wang W, et al. Inhibiting astrocytic activation: A novel analgesic mechanism of ketamine at the spinal level? J Neurochem. 2009;109(6):1691-1700. doi:10.1111/j.1471-4159.2009.06087.x 